\title{
A Technique to Measure Students' Mental Approach using Web and Game Based E-Learning Application
}

\author{
Awais K. Jumani ${ }^{1,}{ }^{*}$, Mashooque A. Memon ${ }^{2}$ and Muneer A. Kartio ${ }^{1}$ \\ 'Department of Computer Science, Shah Abdul Latif University, Khairpur Mirs Pakistan \\ awaisjumani@yahoo.com; kartiomuneer@gmail.com \\ ${ }^{2}$ Department of Computer Science, Benazir Bhutto Shaheed University, Layari, Karachi \\ pashamorai786@gmail.com \\ *Correspondence: awaisjumani@yahoo.com
}

Received: 15 ${ }^{\text {th }}$ May 2018; Accepted: 10 ${ }^{\text {th }}$ June 2018; Published: $1^{\text {st }}$ July 2018

\begin{abstract}
With the advent of E-Learning (Electronic Learning) and M-Learning (Mobile Learning), many educational software or tools have been developed, a major part of which are game-based applications. Even though, most of which are freely available on the web, there are only few intuitions make practical and effective use of these learning applications. Because these applications utilises various elements of multimedia such as audio, video, image and animation, they help visualise the learning materials and hence have higher span of at attention. To investigate the effect of web and game based E-Learning and M-Learning, an experiment was conducted amongst the students of three different schools in Pakistan and the results were analysed. The results of our research reveal that utilisation of such web and game based learning tools are much more effective compared to the traditional teaching methods without applying any ICT (Information and Communication Technology) tools.
\end{abstract}

Keywords: Game Based Learning; Game Design; E-Learning; M-Learning; Graphical User Interface

\section{Introduction}

The $21^{\text {st }}$ century has observed the emergence of new broadcast media. With the passage of time, the cost of digital media has gone down while the access to the information has widened significantly. Although at a little slower rate, developing countries have also observed this phenomenon. The new generation of people, i.e. the young stars, are connecting with new media of internet at an accelerated rate, especially by making use of freely available open platform tools. Education policy makers gradually recognize that it is in their awareness to address these expansions in order to tolerate social constancy and accomplish development. To allow mentors to provide better opportunities concerning their students, methodology which evolving with new media like digital games, and programme could be more effective and helpful. The time of 21st century is make such type of changing and students are more attractive with digital media and new technologies, in education mentors are taking help with new technology which attract every student for understanding better education. 
Now a days, the use of digital games for learning and teaching has become an important aspect of research as many educational institutions are considering them as a catalyst in providing better and effective education. In fact, the application of digital games for effective learning and teaching methods were advocated long before [11,12]. The early adopters of game based learning methodology are paying an important role in supporting mutual understanding as well as in troubleshooting and eliminating the problems rising from the application of game based teaching and learning methodologies due to various reasons which were not previously known. Squire [13] conducted a detailed investigation into the educational use of games in schools. His research explores how application of games provides with new ways understanding while closely looking into the problems associated with this in terms of their real life use and impact. Digital games have been effectively used for teaching many subjects such as mathematics, science and languages, especially in Mobile Assisted Language Learning (MALL)[22,23]. However, regardless of subjects, a wide implementation of digital games in educational institutes is very important as the students are showing great interests in colours and graphical user interface.

\section{Game Based Learning}

Game based learning providing better atmosphere in learning context and kids students are more interested to use such type of games which give them knowledge with extra graphical atmosphere so they like play these exams in educational institutes. They also provide such types of games where kids can recognize their object and facing user interface, game based learning tools gives more attraction towards the kids and kid's wants to learn these things happily.

Game based learning encourage kids student to make confidence to touch technology of 21st century, with the gamed based learning kids mind will be boost through the technology and they make more attention to learning such type of games. Game based teaching and learning methodology will more attract to students and they will realize the real complex problems and solving with the technology based.

Early traditional Learning method cannot more effect on kid's student mind "Fig.1." shows the Traditional learning methods which being implemented.

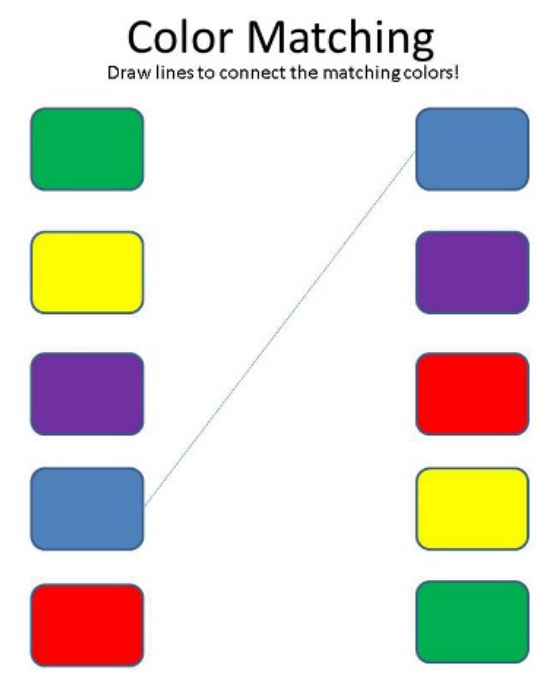

Figure 1. Traditional Learning Method.

\section{Literature Review}

It is observed that few work has been done by researchers in this domain.

Hercules [1], through his research, advocated that digital game based learning is better than general education objectives, during the implementation of based learning and teaching students gives more attention to it and it is also observed student's results are good as compare to general 
teaching methods. Whenever learning and teaching with game based than students can drawing on it and make something different whatever they want so it is positive sign of better education system in our society. Moreover, Ching [2] has surveyed that two modes of game based learning in our education system, collectively and isolated so during the experiments fifty seventh student were participated but there is no any big different on that modes results. Game based learning approaches gives many ideas regarding science and it is mindfully, in collaboratively game based learning approach gives one important fact that student can share their problem or getting suggestion with each other. Also, Yusoff [3] has presented that game based learning approaches of mathematics in Malaysia, primary students were tested and they give positive results in that approaches. It is best approach for weak student in mathematics, whenever it experimented on that students give better results as compare to general education. Prototyping of that application consist on simple numbering systems, addition, and syllabus wise lectures, specially this prototype design for those student which gives more attention on tablets, mobiles and computers. Equally, Oskar [4] has proposed that game based learning practice in mathematics, improving the confidence level of students through the game based approach and also this research surveyed that game based learning approach is best of all student or not. So using the game based learning approach in class room, it gives positive result of less confidence student's. Correspondingly, Begona [5] has considered that electronic games are very important in children atmosphere, through the electronic games children's are improving their education very fast because game based learning give them convenient environment and graphical user interface.

Jennie [6] has analysed the level of fifth class student's, for measuring the improvements of students have iPads which contain many facility during the examining all students gave good results in class rooms. They learning different activities regarding study through internet and game based applications. Respectively, Rudy [7] has considered that 10 guidelines for video game based learning in class room which provide also virtual class rooms and that is more effective learning methodology among the students. Online games regarding education can be improved because their positive effectiveness on students. Consistently, Nicola [8] has described the positive impact of computer game based e-learning for higher education, during the assumption it shows that computer game based e-learning some time works and some it uses for leisure. This study shows that motivation of student who did not take part in using computer game based learning. Likewise, Jui [9] has explored that applying game based approach in classes, during the implementation of game based approach they were divided into two categories which one is experimental of game based learning and other was traditional teaching methodology. While getting the results experimental group gives positives results as compare to traditional teaching methodology. Similarly, Yi-Kai [10] has implemented game based approach among the green building students while the testing they were divided into two groups which is experimental group and control group. For getting the results they were distribute the paper based questions so the experimental groups gives more positives answers as compare to control group. Soomro $[15,16]$ has analysed the future E-learning experiences. Something better tools.

Bhuiyan et al. [17-18] demonstrated that the application of game based M-Learning generally increases the learning efficiency of the special needs children. Their research also advocates that these applications can be used tracking and monitoring the overall development process of the special needs students.

Miraz et al. [19-20] studied the impact of culture on the usage of E-Learning and M-Learning. A prototype, namely "Mobile Academy", was developed to conduct cross-cultural usability analysis. Their research shows that the cultural affiliations of the users have significant impact on the adoption and diffusion trends [21] of any such applications.

\section{Architecture of Kids E-Zone}

In this proposed framework, as shown in Figure 2, the users first start the KIDS E-Learning Web application, if started Kids E-Learning web application than main screen shows the 5 level of Kids Learning lessons. All levels are collaborative with each other first level clear than other one will be 
unlock. Step by step all levels will be unlock by user who are using that web application. All levels have different Colour choosing exercises.



Figure 2. Architecture of Kids E-Zone

\section{Develop Web Application}

In the beginning of time, implementation of web application on the basis of intranet. Furthermore, C\# integrated development environment along with ASP.Net technology. Cascade style sheet is played a crucial role for designing the application interface. Proposed application based on few tabs which are given below with its description.

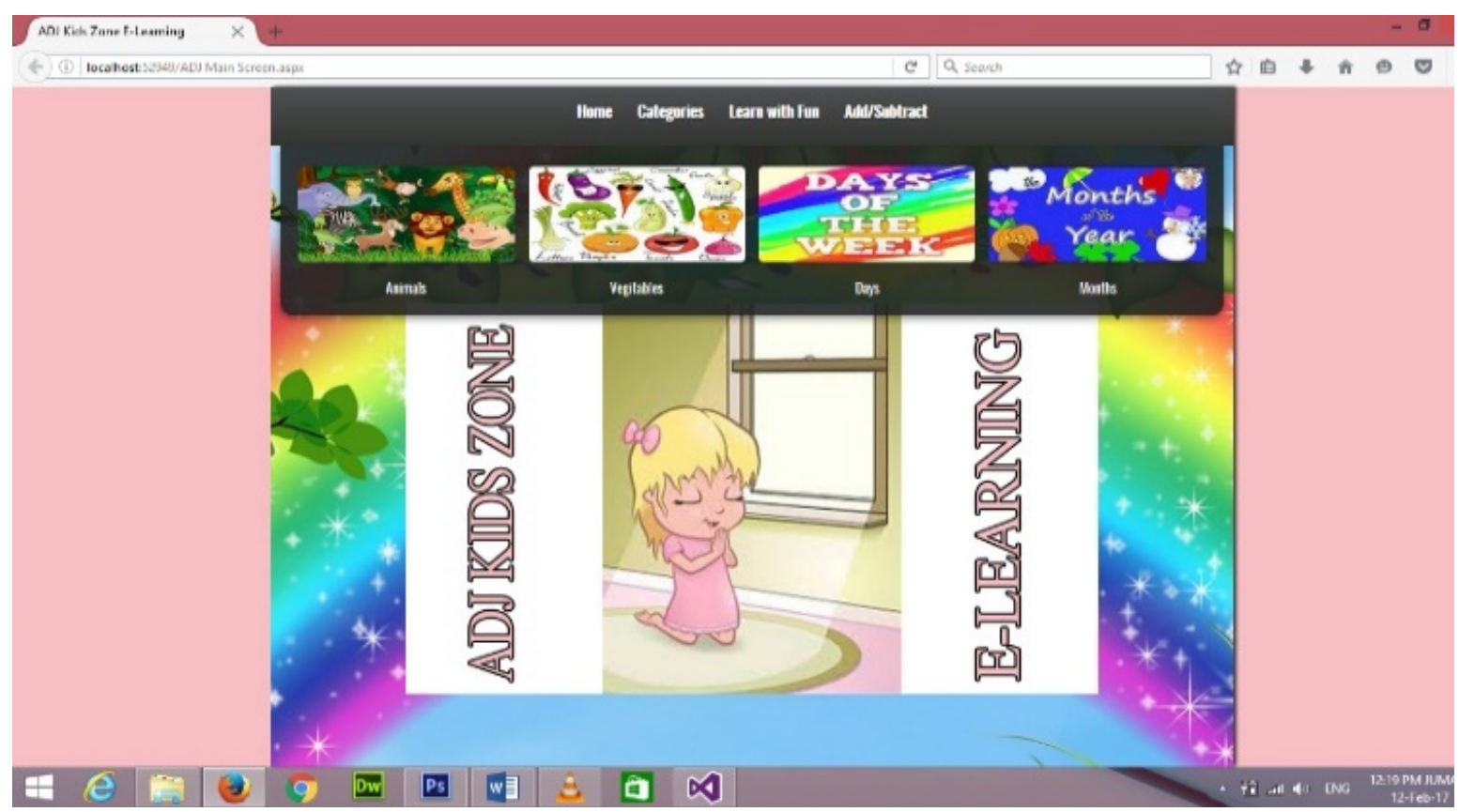

Figure 3. Illustrates Dashboard of Kids Zone

Some snapshots of developed web application are demonstrated in Figure 3, 4 and 5. As shown in Figure 3, user can choose the category and see the different stages of learning. Each stage can be created as like as kids mentality approach with lot of graphically interaction.

As shown in Figure 4, the students can see animal section where they choose animal so it shows animal name and their sound and also user can store the more different animals manually. These animal "GIF" images can be move and also shows the audio voices when it is clicked so it is more helpful for kids to know animal voices. 


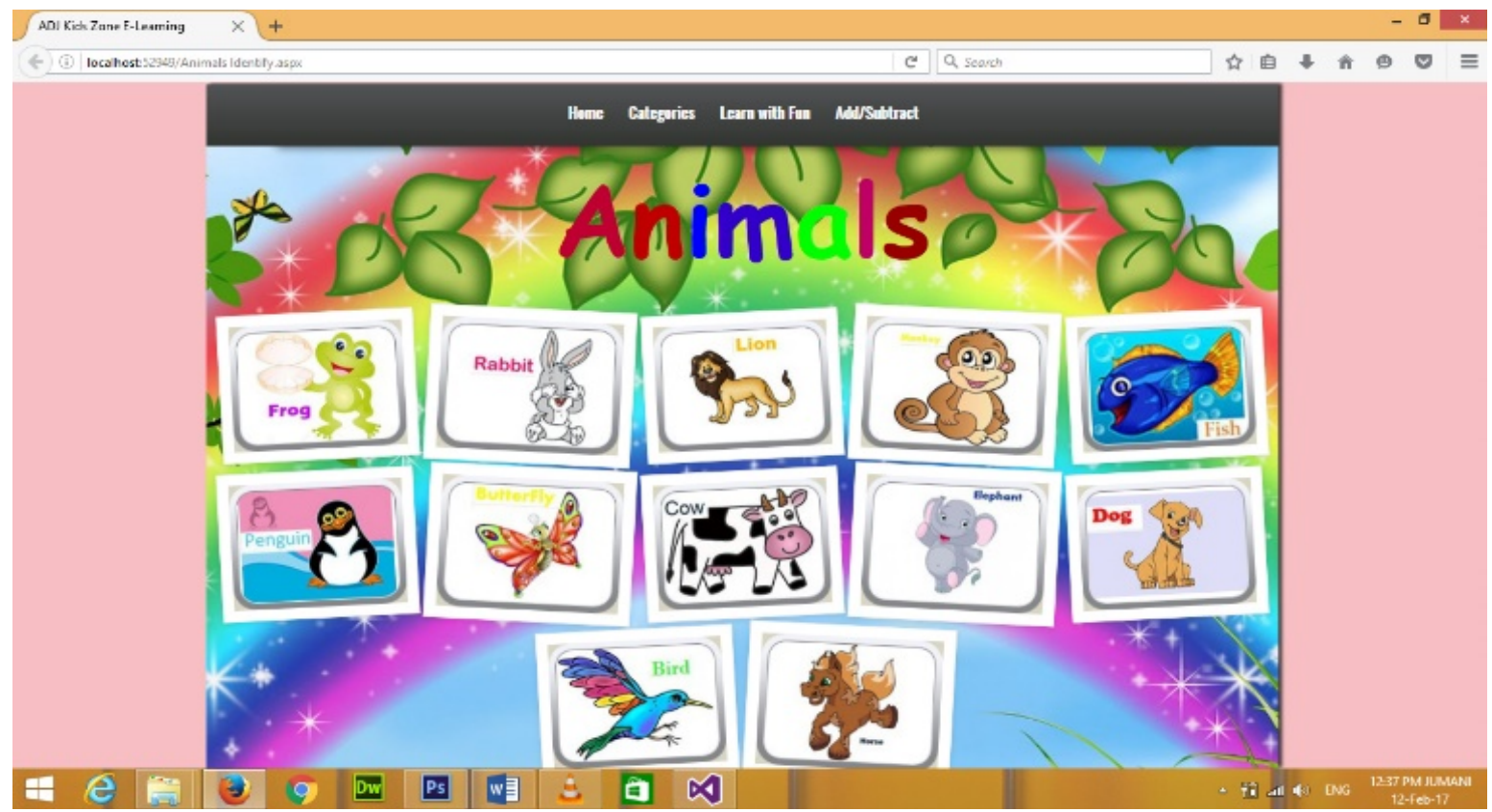

Figure 4. Displays Animal Identification.

As shown in Figure 5, user can choose the nursery rhymes and these rhymes are stored in our database with sound and Graphics Interchange Format "GIF" images. These rhymes are stored in our database and step by step their audio voices are stored so kids can easily understand the pronunciation of the words easily.

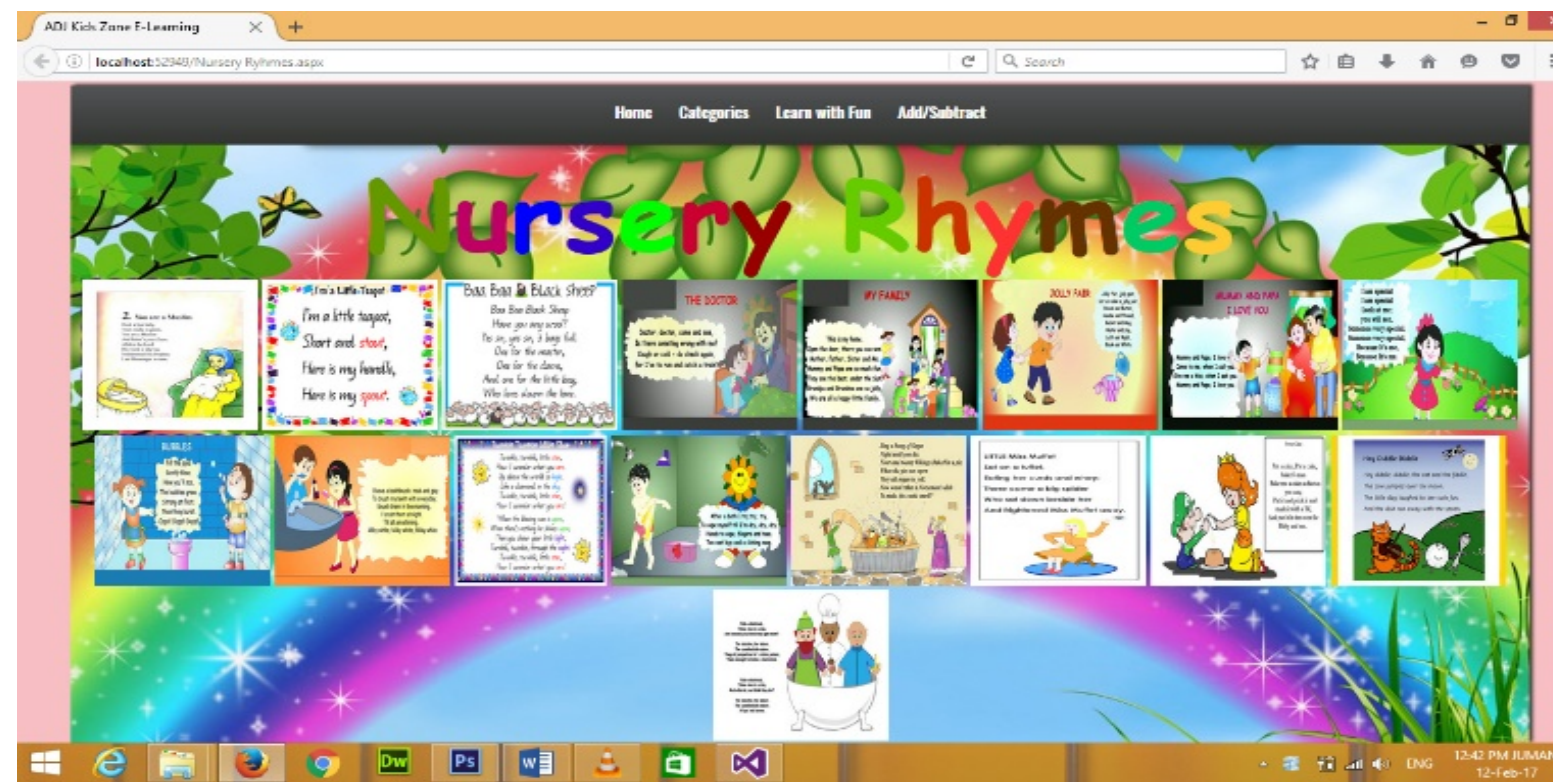

Figure 5. Displays Nursery Rhymes

\section{Results}

For the evaluation of the proposed framework and developed web application. It is implemented and taking results from three schools which is shown in "Table 1", "Table 2" and "Figure. 6". So it is tested on 70 kids simultaneously and among these schools, first schools it is taken 12 male students and 13 female students. Second schools for the implementation of web based learning it is taken 14 male students and 11 female students. Thirds school it is taken 9 male students and 11 female students and achieved positive results. 
Table 1 Students Ratio

\begin{tabular}{|l|l|}
\hline \multicolumn{2}{|l|}{ Kids University Khairpur Mirs } \\
\hline Male Kids & 12 \\
\hline Female Kids & 13 \\
\hline Sajjad Model School Khairpur Mirs \\
\hline Male Kids & 14 \\
\hline Female Kids & 11 \\
\hline Al-Naseer Educational Foundation Khairpur Mirs \\
\hline Male Kids & 9 \\
\hline Female Kids & 11 \\
\hline
\end{tabular}

This web application implement on three different educational schools and taking below results. So we have taken such kind of results with test of kids. From the Kids University Khairpur Mir's it is calculated male kids ratio $94.3 \%$ gives positive results and $5.7 \%$ gives negative results and $97.9 \%$ female kids gives positive results and 2.1\% gives negative results. From the Sajjad Model Public School Kahirpur Mir's it is calculated male kids ratio $88.9 \%$ gives positive results and $11.1 \%$ gives negative results and female kids gives $91.6 \%$ gives positive result and $8.4 \%$ gives negative results, in the last Al-Naseer Educational Foundation Khairpur Mir's it is calculated male kids ratio $96.2 \%$ gives positive results and $3.8 \%$ gives negative result and female kids give $95.7 \%$ positive results and $4.3 \%$ gives negative results.

Table 2 Respondents Satisfaction Ratio

\begin{tabular}{|c|c|c|}
\hline & Positive & Negative \\
\hline \multicolumn{3}{|c|}{ Kids University Khairpur Mirs } \\
\hline Male Kids & 94.3 & 5.7 \\
\hline Female Kids & 97.9 & 2.1 \\
\hline \multicolumn{3}{|c|}{ Sajjad Model Public School Khairpur Mirs } \\
\hline Male Kids & 88.9 & 11.1 \\
\hline Female Kids & 91.6 & 8.4 \\
\hline \multicolumn{3}{|c|}{ Al-Naseer Educational Foundation Khairpur Mirs } \\
\hline Male Kids & 96.2 & 3.8 \\
\hline Female Kids & 95.7 & 4.3 \\
\hline
\end{tabular}

During the implementation of Kids eLearning web application of these schools, it is compare with general education learning methods and game based learning methods so it is prove that game based learning methods effects more better from the general board based learning methods.

\section{Conclusions}

It is now well established that technology is paying an important role in our education system. With the help of technology, education system can be developed significantly. Now-a-days, many institutions use ICT in teaching and delivering lectures which result in efficient learning. Actual eLearning comes from using information communications technology to enlarge educational prospective. While conducting testing and evaluation of "e-Zone", it has been observed that lot of children showed higher interest towards visualize learning methods and they enjoyed the study as compare to traditional learning methods. Game based learning methods were also found to be more effect on the mental development process of the children. Future research will involve conducting a experiments amongst a wider range of audiences as well as inclusion of various other multimedia elements. 


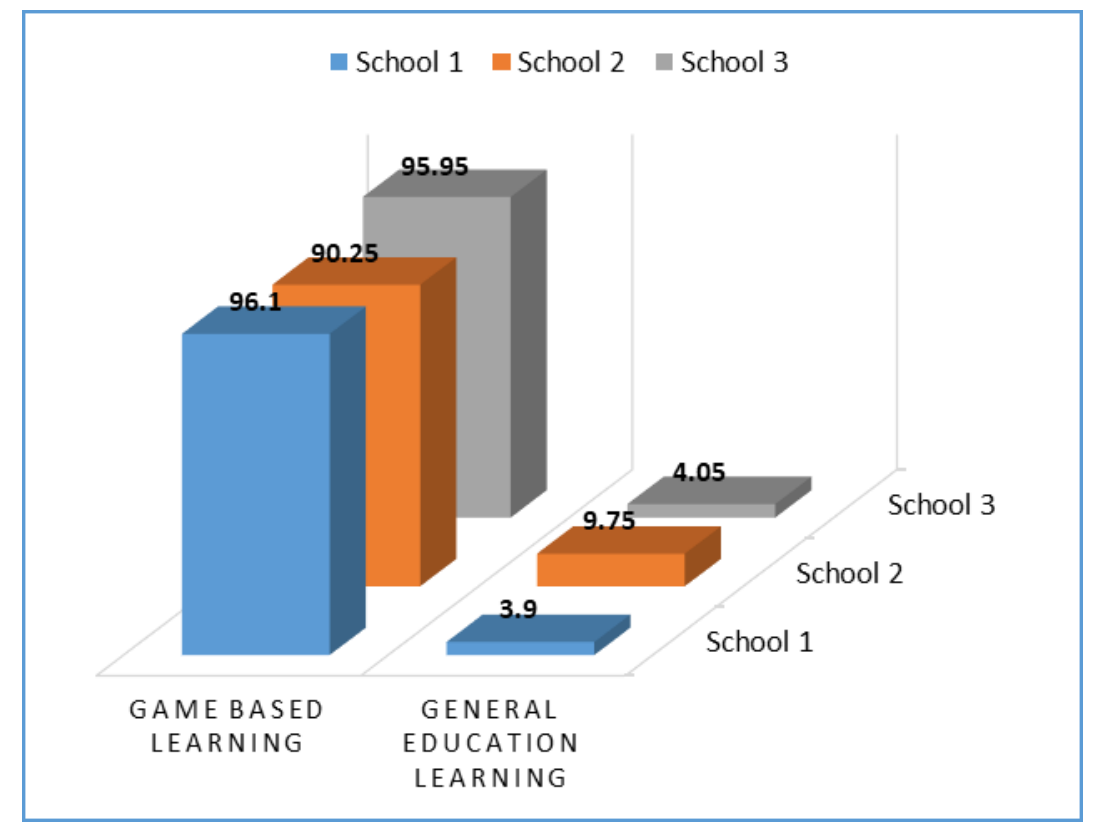

Figure 6. Comparison of General Education learning and Game based learning

\section{References}

[1] Panoutsopoulos.H, Sampson.D.G., “A Study on Exploiting Commercial Digital Games into School Context", International Forum of Educational Technology \& Society (IFETS), Vol. 15, No. 1, pp.15-27, 2012.

[2] Chen.C.H., Wang.K.C., Lin.Y.H., “The Comparison of Solitary and Collaborative Modes of Game-based Learning on Students' Science Learning and Motivation", International Forum of Educational Technology \& Society (IFETS), Vol. 18, No. 2, pp.237-248, 2015.

[3] Hussain.S.Y.S., Tan.W.H., Idris.M.Z., “Digital Game-Based Learning for Remedial Mathematics Students: A New Teaching and Learning Approach in Malaysia", International Journal of Multimedia and Ubiquitous Engineering, Vol. 9, No. 11, pp.325-338, 2014.

[4] Chen.O.K.S.Y., Wu. D.H., Lao.A.C.C., Chan.T.W., “The Effects of Game-Based Learning on Mathematical Confidence and Performance: High Ability vs. Low Ability", International Forum of Educational Technology \& Society (IFETS), Vol. 17, No. 3, pp. 65-78, 2014.

[5] Gros.B, "Digital Games in Education: The Design of Games-Based Learning Environments", Journal of Research on Technology in Education, Vol. 40, No. 1, pp. 23-38, 2007.

[6] Carr.J.M., “Does Math Achievement h'APP'en when iPads and Game-Based Learning are Incorporated into Fifth-Grade Mathematics Instruction?" Journal of Information Technology Education: Research, Vol. 11, pp. 271-286, 2012.

[7] R.McDaniel, P.Telep, “Best Practices for Integrating Game-Based Learning into Online Teaching”, MERLOT Journal of Online Learning and Teaching, Vol. 5, No. 2, pp. 424-438, 2009.

[8] Whitton.N, "Motivation and computer game based learning", Proceedings ascilite Singapore 2007.

[9] J.M.Yien, C.M.Hung, G.J.Hwang, “A Game-Based Learning Approach To Improving Students' Learning Achievements In A Nutrition Course", Tojet: The Turkish Online Journal Of Educational Technology, Vol. 10, No. 2, Pp.1-10, 2011.

[10] Juan.Y.K,Chao.T.W, “Game-Based Learning for Green Building Education”, Sustainability Vol. 7, 2015.

[11] Scott.B.S.A., Siyahhan.B, “Transformational play as a curricular scaffold: Using videogames to support science education", Journal of Science Education and Technology, Vol. 18, pp. 305-320, 2009. 
[12] Gee.J.P, “What video games have to teach us about learning and literacy”, Palgrave Macmillan, New York, 2003.

[13] Squire.K.D., "Changing the game: What happens when videogames enter the classroom?” Innovate, Vol. 1, No. 6, 2005.

[14] Shaffer.D.W., “How Computer Games Help Children Learn”, Palgrave Macmillan, New York, 2006.

[15] Alwani, A. E. S., \& Soomro, S. "Barriers to effective use of information technology in science education at Yanbu Kingdom of Saudi Arabia", In E-learning experiences and future, InTech, 2010.

[16] Soomro, S., "E-Learning Experiences and Future”, InTech. 41 Madison Avenue 31st Floor, New York, NY 10010, 2010.

[17] Moniruzzaman Bhuiyan, Ambreen Zaman and Mahdi H. Miraz, "Usability Evaluation of a Mobile Application in Extraordinary Environment for Extraordinary People", in the proceedings of the International Conference on eBusiness, eCommerce, eManagement, eLearning and eGovernance (IC5E 2014), held at University of Greenwich, London, UK, 30-31 July, 2014 . Available: https://arxiv.org/ftp/arxiv/papers/1708/1708.04653.pdf.

[18] Monir Bhuiyan, Mahdi H. Miraz and Likhon Banik, "Automated Generation of Learning Materials for Children with Special Needs in Converged Platforms Using Android", in Advanced and Applied Convergence Letters (AACL): Advanced and Applied Convergence and Advanced Culture Technology, ISSN: 2288-6060, vol. 3, pp. 246-249, published by The Institute of Internet, Broadcasting and Communication, Jeju Island, Korea, 13 November 2014.

[19] Mahdi H. Miraz, Maaruf Ali and Peter S. Excell, “Cross-cultural Usability Issues in E/M-Learning”, Annals of Emerging Technologies in Computing (AETiC), Print ISSN: 2516-0281, Online ISSN: 2516-029X, pp. 4655, Vol. 2, No. 2, 1st April 2018, Published by International Association of Educators and Researchers (IAER), Available: http://aetic.theiaer.org/archive/v2n2/p5.html.

[20] Mahdi H. Miraz, Sajid Khan, Monir Bhuiyan and Peter Excell, "Mobile Academy: A Ubiquitous Mobile Learning (mLearning) Platform", in the proceedings of the International Conference on eBusiness, eCommerce, eManagement, eLearning and eGovernance (IC5E 2014), held at University of Greenwich, London, UK, 30-31 July 2014, pp. 89-95. Available: http://edlib.asdf.res.in/2014/ic5e/ic5e2014014.pdf.

[21] Maaruf Ali and Mahdi H. Miraz, "The Cultural Impact of Diffusion of IT Innovation in World Society", in the proceedings of The International Conference on Recent Advances in Computer Systems (RACS-2015) held at University of Ha'il, Ha'il, KSA, DOI: 10.2991/racs-15.2016.19, ISBN: 978-94-6252-146-9, ISSN: 2352538x, 30 November - 1 December 2015, pp 114-118, Published by Atlantis Press, Available: http://www.atlantis-press.com/php/paper-details.php?id=25847792.

[22] Shayma K. Miraz, Maaruf Ali, "An Overview of Mobile Assisted Language Learning (MALL)" in the proceedings of the International Conference on eBusiness, eCommerce, eManagement, eLearning and eGovernance (IC5E 2014), held at University of Greenwich, London, UK, 30-31 July 2014, pp. 67-70, Available: $\underline{\text { http://edlib.asdf.res.in/2014/ic5e/ic5e2014010.pdf. }}$

[23] Maaruf Ali and Shayma K. Miraz, "Mobile Assisted Language Learning (MALL) - A Brief Survey", Annals of Emerging Technologies in Computing (AETiC), Print ISSN: 2516-0281, Online ISSN: 2516-029X, pp. 3745, Vol. 2, No. 2, 1st April 2018, Published by International Association of Educators and Researchers (IAER), Available: http://aetic.theiaer.org/archive/v2n2/p4.html.

(C) 2018 by the author(s). Published by Annals of Emerging Technologies in Computing (AETiC), under the terms and conditions of the Creative Commons Attribution (CC BY) license which can be accessed at http://creativecommons.org/licenses/by/4.0/. 